\title{
Akkadian in context
}

The traditional, philological approach assumes that ancient Akkadian texts are studied for their meaning and that the analysis of their social and cultural significance is carried out within their respective genres. I would, however, like to propose after Verschueren (2012) that discourse - or language in use - is formed by a multitude of interacting and interconnected texts from different genres, and that investigating them within their communicative context, discoursive context, and genre context, as well as external social, cultural and political context can provide us with many new insights about the nature of communicative practices in the Ancient Near East, as well as shed new light on the new meaning of the texts themselves. When we take into account the contextual embeddedness of every act of communication, its entire background emerges from behind the cuneiform wedges: the speaker/writer, the addressee/reader, their agendas, the social mores that influence their behaviour, and the silent but powerful assumptions that they operate under. The talk would be illustrated with several examples from the first and second millennium textual sources, showing how assuming broader perspective and at the same time switching perspectives makes it possible to evaluate our data more accurately. 